\title{
CONTABILIZANDO CONHECIMENTO: CAPACITANDO ESTUDANTES DO ENSINO MÉDIO A GERENCIAR PROCESSOS EMPRESARIAIS
}

\section{ARTIGO ORIGINAL}

SOUZA, Fábio Henrique de ${ }^{1}$

NINA, Ariadson João ${ }^{2}$

OLIVEIRA, Edgar Moreira ${ }^{3}$

CARVALHO, Emanuele Camile Cardoso ${ }^{4}$

NASCIMENTO, Fabíola Pereira do ${ }^{5}$

SOUZA, Fábio Henrique de. Et al. Contabilizando Conhecimento: Capacitando estudantes do Ensino Médio a gerenciar processos empresariais. Revista Científica Multidisciplinar Núcleo do Conhecimento. Ano 05, Ed. 10, Vol. 08, pp. 158175. Outubro de 2020. ISSN: 2448-0959, Link de acesso: https://www.nucleodoconhecimento.com.br/contabilidade/contabilizandoconhecimento

\section{RESUMO}

Este trabalho surgiu da necessidade dos estudantes do ensino médio do IEMA UP Bacabeira, entenderem a complexidade gerencial das empresas e de que forma esses

${ }^{1}$ Especialista em Docência do Ensino Superior, Contador, Produtor Cultural e Pós graduando em Contabilidade e Planejamento Tributário.

2 Estudante do Terceiro ano do curso técnico de administração.

${ }^{3}$ Estudante do Terceiro ano do curso técnico de administração.

${ }^{4}$ Estudante do Terceiro ano do curso técnico de administração.

${ }^{5}$ Estudante do Terceiro ano do curso técnico de administração. 
conhecimentos podem ser favoráveis para a entrada no mercado de trabalho. Neste contexto, profissionais que entendem os softwares, práticas digitais e ferramentas de controle gerencial demonstram um perfil desejável para essas áreas e tendem a ter melhores oportunidades. Adaptando o perfil desses estudantes à realidade das empresas seria possível contribuir para a sua preparação, valorização e reconhecimento pela sua capacidade técnica. A pesquisa aborda a gestão empresarial junto aos estudantes dos cursos de administração e logística. Assim, pretende-se capacitá-los em práticas financeiras, fiscais e contábeis a fim de contribuir para a entrada no mercado de trabalho e obtenção de renda. Etapas iniciais do projeto: 1- levantamento bibliográfico; 2- treinamento de monitores sobre sistemas gerencias; 3- edital de seleção; 4- seleção via prova escrita; e 5- Divulgação dos aprovados. Além disso, aplicou-se um questionário socioeconômico e outro sobre as dificuldades no estágio profissional, visando a uniformidade nos resultados. $\mathrm{O}$ trabalho divide-se em duas etapas, a primeira com atividades introdutórias e a segunda com 3 módulos (financeiro, fiscal e contábil) com duração de 12 meses e carga horária semanal de 60 minutos, totalizando 60 horas. As avaliações modulares valem de zero a dez pontos e as atividades acontecem no laboratório de informática e auditório. Ao final, serão analisados os dados e apresentados os indicadores de resultado, seguidos por um relatório com os aspectos relevantes para apresentação junto com a certificação.

Palavras-Chave: emprego, capital intelectual, educação profissional.

\section{INTRODUÇÃO}

Trata-se de um projeto de pesquisa e extensão que aborda conhecimentos técnicos sobre a gestão financeira, fiscal e contábil de empresas junto a estudantes do ensino médio dos cursos de administração e logística do Instituto de Educação, Ciência e Tecnologia do Maranhão (IEMA) Unidade Plena de Bacabeira para que estes venham a compreender a complexidade da gestão empresarial moderna e conhecimentos técnicos importantes para seu desenvolvimento profissional. Dentre os fatores mais relevantes para a realização deste trabalho podemos citar a grande competitividade não somente entre as empresas, mas também no mercado de trabalho atual, ambos 
cada vez mais exigentes quanto à competência de seus colaboradores, que por sua vez, precisam estar capacitados para suprir essa demanda mercadológica. Tal situação atrelada ao fato de estudantes estagiários relatarem a necessidade de um conhecimento mais específicos no que diz respeito as notas fiscais, elaboração de planilhas de cálculos e análises de relatórios financeiros acabou dando origem ao desenvolvimento deste projeto. Em seu decorrer são trabalhados o uso de softwares, plataformas digitais, ferramentas gerenciais, cálculos lógicos e práticas de auditoria a fim de adaptar o perfil dos estudantes à realidade da gestão empresarial moderna.

\section{METODOLOGIA}

A pesquisa apresenta-se como um relato de experiência com prática pedagógica, abordagem qualiquantitativa, descritiva e baseada em pesquisa bibliográfica que está sendo realizado com estudantes da $2^{\circ}$ série, dos cursos técnicos de administração e logística, no IEMA UP Bacabeira. O trabalho foi dividido em duas etapas, sendo que na primeira se deu da seguinte forma:

Tabela 1 - Atividades da primeira etapa do projeto.

\begin{tabular}{|c|c|c|c|}
\hline Tipo de atividade & $\begin{array}{l}\text { Carga } \\
\text { Horária }\end{array}$ & Período & Ano \\
\hline $\begin{array}{l}\text { Seminário - Orçamento Público: entendendo o } \\
\text { Plano Plurianual (PPA), a Lei de Diretrizes } \\
\text { Orçamentárias (LDO) e Lei Orçamentária Anual } \\
\text { (LOA). }\end{array}$ & $4 \mathrm{~h}$ & $\begin{array}{l}1^{\circ} \\
\text { Semestre }\end{array}$ & 2019 \\
\hline $\begin{array}{l}\text { Oficina - } 1^{\text {a }} \text { Vivência de Contabilidade do IEMA } \\
\text { UP de Bacabeira. }\end{array}$ & $4 \mathrm{~h}$ & $\begin{array}{l}1^{\circ} \\
\text { Semestre }\end{array}$ & 2019 \\
\hline $\begin{array}{l}\text { Minicurso: declaração de imposto de renda } \\
\text { pessoa física DIRPF } 2019 \text {. }\end{array}$ & $4 \mathrm{~h}$ & $\begin{array}{l}10 \\
\text { Semestre }\end{array}$ & 2019 \\
\hline $\begin{array}{l}\text { Palestra - Logística Legal: conhecendo os } \\
\text { tributos e incentivos fiscais aplicados à } \\
\text { agroindústria no Maranhão. }\end{array}$ & $4 \mathrm{~h}$ & $\begin{array}{l}2^{\circ} \\
\text { Semestre }\end{array}$ & 2019 \\
\hline
\end{tabular}




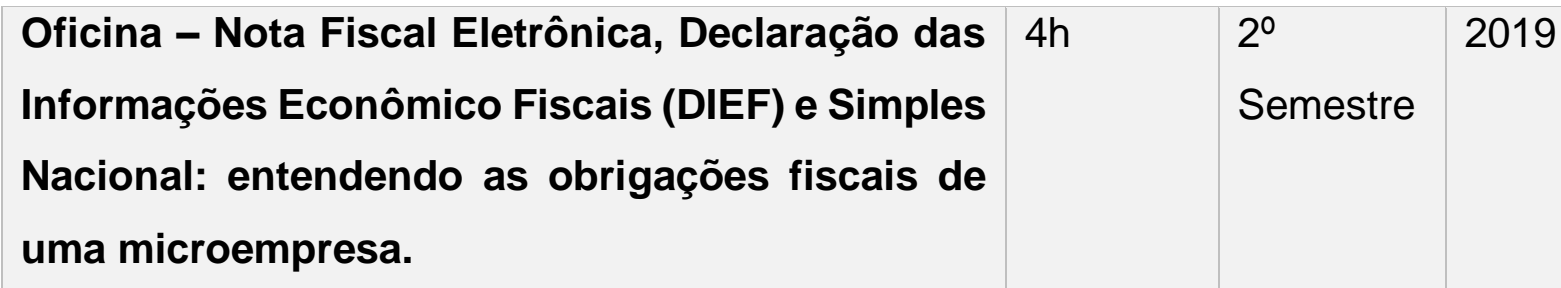

Fonte: elaborado pelo autor.

Já a segunda etapa contempla a capacitação nos 3 módulos propostos (financeiro, fiscal e contábil) mais atividades complementares (Tabela 2). Os professores responsáveis realizaram levantamento bibliográfico e escolha dos conteúdos abordados na seleção de estudantes para esta capacitação, seguido de treinamento da equipe de monitores composta por 4 estudantes selecionados mediante rendimento acadêmico. Posteriormente, foi realizada a divulgação na $2^{2}$ série dos cursos técnicos de logística e administração sob forma de edital (elaborado pela gestão da escola). Os inscritos na seleção realizaram o teste avaliativo (APÊNDICE II) contendo 10 questões discursivas abordando conteúdos sobre matemática financeira, raciocínio lógico, conhecimentos fiscais, contabilidade e informática e tiveram sua classificação divulgada nos murais da escola. O processo seletivo tem como público alvo os estudantes da $2^{\underline{a}}$ série dos cursos técnicos de Logística e Administração, sendo que os interessados devem preencher ficha de inscrição e realizar o teste avaliativo para concorrer as 20 vagas. $O$ objetivo da seleção é verificar o nível de conhecimento destes estudantes e selecionar os que realmente têm interesse pela capacitação. Além disso, deduz-se que o número de vagas reduzido proporciona melhor aproveitamento do conteúdo e torna melhor o alcance do aprendizado dos participantes.

Tabela 2: Atividades modulares e complementares da segunda etapa do projeto.

\begin{tabular}{|l|l|l|l|}
\hline Módulos propostos & $\begin{array}{l}\text { Carga } \\
\text { horária }\end{array}$ & Período & Ano \\
\begin{tabular}{ll|l} 
Capacitação - módulo financeiro: cadastro de \\
produtos, serviços, fornecedores e clientes,
\end{tabular} & $\begin{array}{l}2^{0} \\
\text { semestre }\end{array}$ & 2019 \\
\hline
\end{tabular}

Disponível em: https://www.nucleodoconhecimento.com.br/contabilidade/contabilizando- 


\begin{tabular}{|c|c|c|c|}
\hline $\begin{array}{l}\text { omposição e inventário de estoque, capital de } \\
\text { iro, desconto, cálculo de juros simples e } \\
\text { omposto e contas a pagar e receber. }\end{array}$ & & & \\
\hline $\begin{array}{l}\text { Capacitação - módulo fiscal: tributos, apuração } \\
\text { tributária, emissão de nota fiscal eletrônica e } \\
\text { consultas fiscais em plataformas digitais. }\end{array}$ & $12 \mathrm{~h}$ & $\begin{array}{l}1^{\circ} \\
\text { semestre }\end{array}$ & 2020 \\
\hline $\begin{array}{l}\text { Capacitação - módulo contábil: composição do } \\
\text { patrimônio, contas de resultado, lançamentos, } \\
\text { elaboração e análise das demonstrações } \\
\text { contábeis. }\end{array}$ & $12 \mathrm{~h}$ & $\begin{array}{l}10 \\
\text { semestre }\end{array}$ & 2020 \\
\hline $\begin{array}{l}\text { Atividades complementares - Aplicação dos } \\
\text { conhecimentos adquiridos sobre os processos } \\
\text { gerenciais nas empresas onde os estudantes } \\
\text { estagiarão pelo programa Vivência } \\
\text { Profissional/Pra Saber Mais, além de produção de } \\
\text { pesquisa acadêmica e outros. }\end{array}$ & $4 h$ & $\begin{array}{l}1^{\circ} \text { e } 2^{\circ} \\
\text { semestre }\end{array}$ & 2020 \\
\hline
\end{tabular}

Fonte: Elaborada pelo Autor.

O projeto tem duração de 12 meses, com carga horária semanal de 60 minutos, totalizando 60 horas. Após o final de cada módulo é realizada uma avaliação que vale de 0 a 10 pontos com simulações de casos práticos para mensuração do aprendizado. As aulas e testes avaliativos estão sendo realizados, a priori, no laboratório de informática e auditório.

Como atividades complementares, caberão aos estudantes comparar e avaliar os procedimentos gerenciais adquiridos durante a realização dos módulos com os que já são aplicados nas empresas que os concedem estagio prévio para que haja uma análise e em seguida um debate sobre eventuais ajustes nos conteúdos propostos, visando que os mesmos possam obter um melhor rendimento no estágio curricular, bem como, na vida profissional e acadêmica. 
Além disso, foi repassado um questionário (adaptado de ENCCEJA, 2013 e DOMINGOS 2012, APÊNDICE I) aos estudantes do projeto e que já estão estagiando nas empresas parceiras do IEMA UP Bacabeira, a fim de identificar o perfil socioeconômico e as dificuldades que estes encontram para trabalhar com informações gerenciais empresariais e que também servirá, junto com os demais aspectos avaliados, como base para o levantamento indicadores a serem apresentados futuramente via transferência dos resultados sob forma de pesquisa, por meio de artigos, divulgação em empresas, apresentações em congressos, simpósios nacionais e internacionais, e mostras fotográficas. Além da promoção de parcerias com empresas e/ou profissionais da área para a realização de palestras e visitas técnicas, buscando promover vivências acadêmicas de área aos estudantes. Entre os recursos necessários estão: biblioteca, laboratório de informática com internet, quadro branco, pincel, apagador, material impresso, projetor, notebook, lousa digital e auditório.

Após a finalização de todos os módulos e atividades complementares será realizada uma análise geral dos dados e apresentação dos gráficos e tabelas em valores absolutos (n) e relativos (\%) elaborados no programa Microsoft Excel 2013. Em seguida, será apresentado o relatório final para equipe escolar, contendo os aspectos mais relevantes do projeto, junto com a entrega da certificação dos estudantes. No tópico a seguir serão apresentados os resultados obtidos até o momento e a discussão dos mesmos.

\section{RESULTADOS E DISCUSSÃO}

Devido a extensão e complexidade dos assuntos relacionados a educação financeira, fiscal e contábil, houve a necessidade de uma abordagem científica inicial (Figura 1), que serviu de embasamento introdutório para os módulos de capacitação. 
Figura 1. Pesquisa bibliográfica para elaboração de oficina sobre contabilidade.

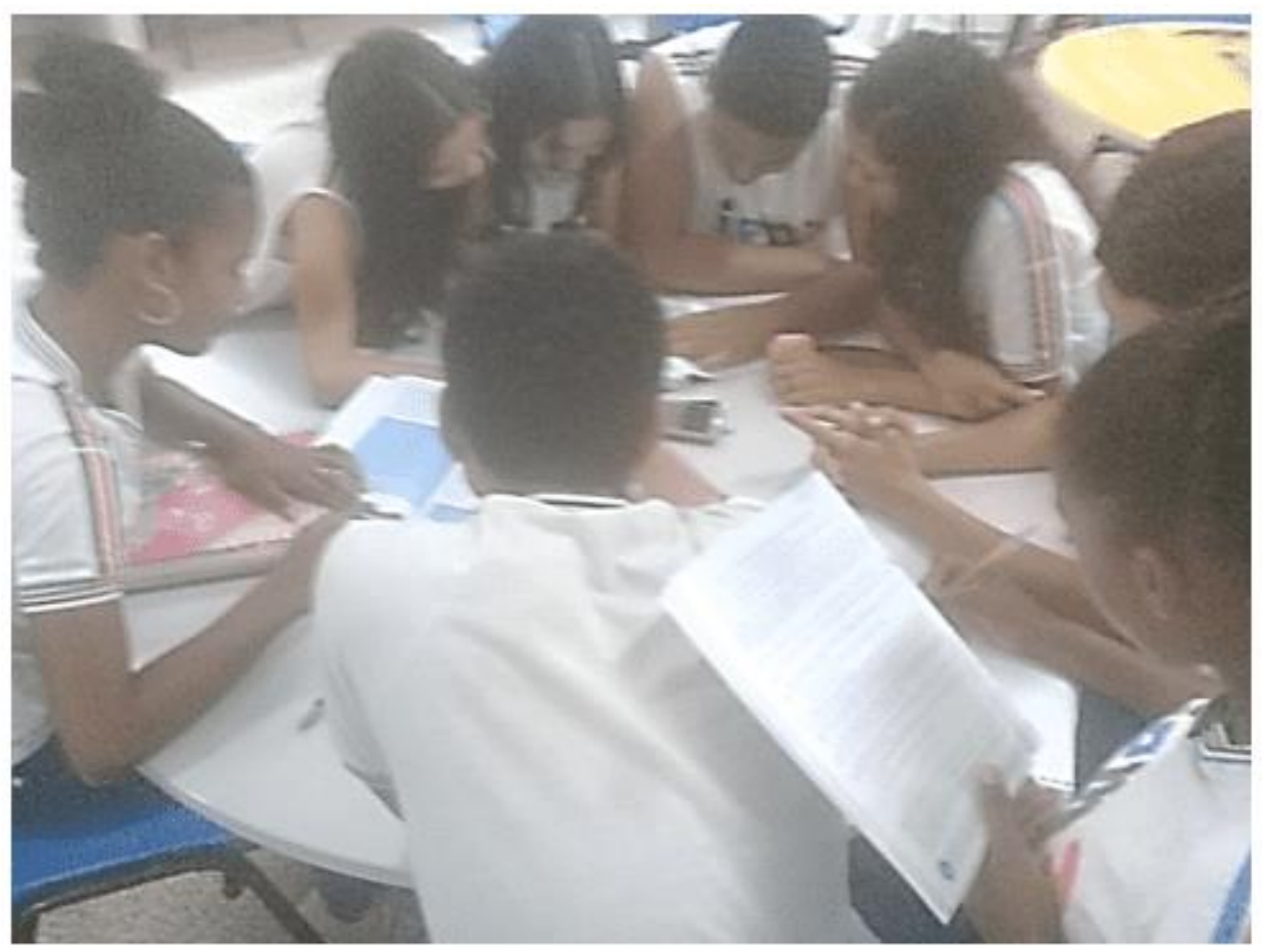

Fonte: Autor, 2019.

Trata-se da $1^{\text {a }}$ etapa do projeto que foi realizada no $1^{\circ}$ semestre de 2019 (Tabela 1). Além disso, foi feita a divulgação via edital, captação de estudantes por ficha de inscrição e seleção mediante teste avaliativo. Após a realização de todo o processo seletivo, foi possível mensurar os primeiros indicadores, conforme abaixo: 
Gráfico 1. Dados do processo seletivo para a capacitação.

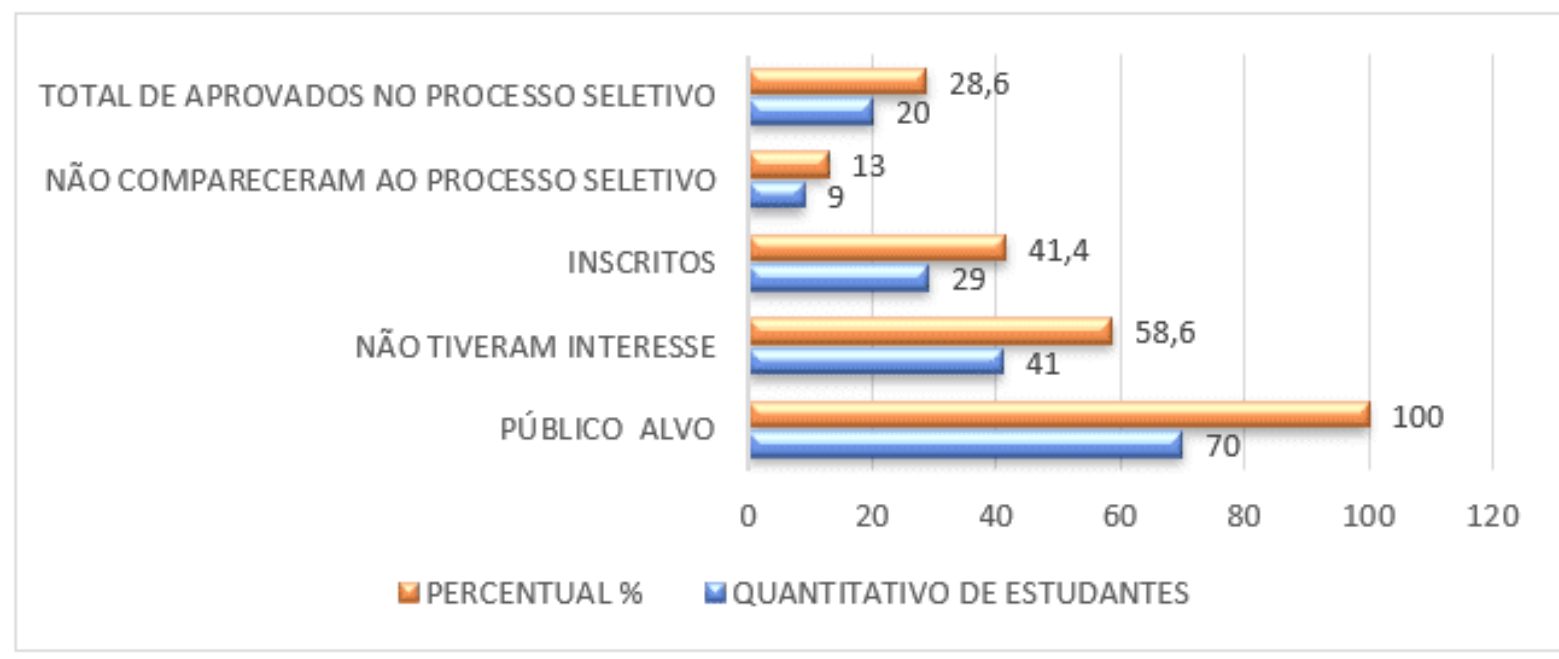

Fonte: Elaborado pelo autor.

O público alvo correspondeu a 70 estudantes e observou-se que a procura pelo seletivo foi equivalente a quase metade dessas pessoas $(41,4 \%)$, o que levanta a hipótese de que há interesse nos conhecimentos em gestão empresarial (Figura 2) pelos alunos da segunda série dos cursos de Logística e Administração do IEMA UP Bacabeira.

Figura 2. Estudantes aprendendo a emitir nota fiscal eletrônica (1 ${ }^{a}$ Etapa).

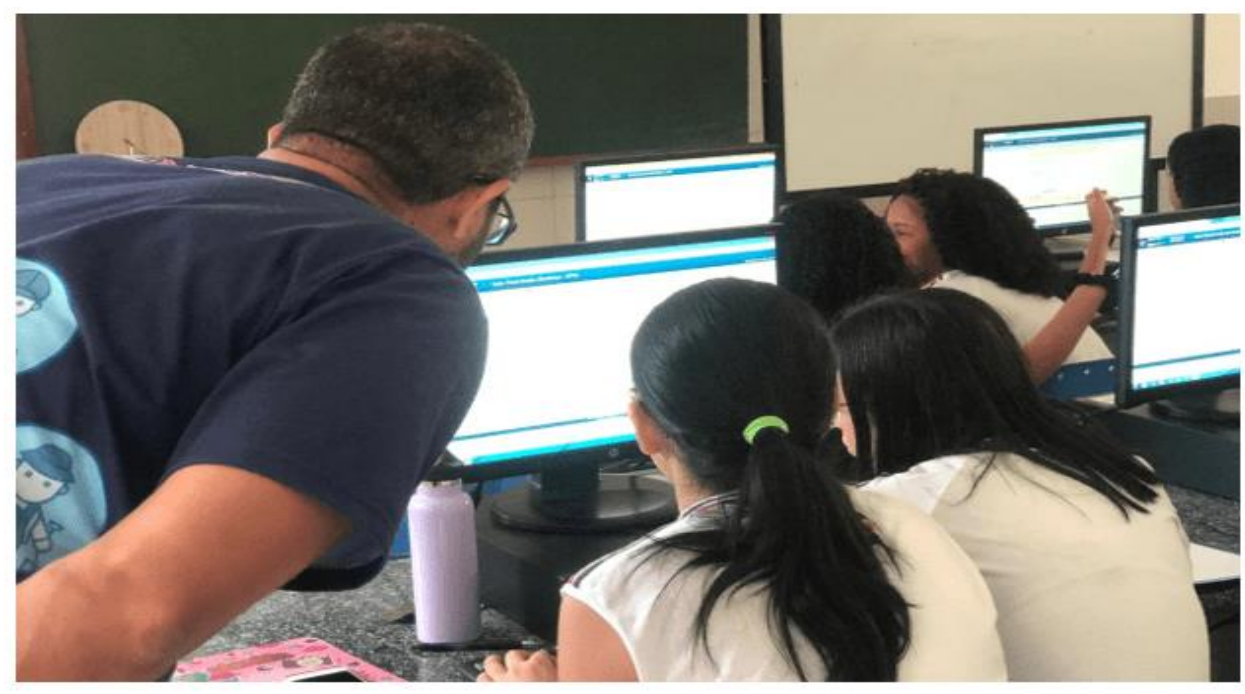

Fonte: Autor, 2019.

RC: 63588

Disponível em: https://www.nucleodoconhecimento.com.br/contabilidade/contabilizandoconhecimento 
O índice de desistência correspondeu a aproximadamente $1 / 3$ do total de inscritos, entretanto, entende-se que a quantidade de disciplinas ministradas na escola, bem como o fato dos alunos estarem sempre participando de visitas técnicas, olimpíadas, eletivas, eventos acadêmicos, gincanas, palestras, cursos e estágios profissionais dentro e fora da escola, pode vir a sobrecarrega-los, o que talvez tenha refletido não somente no percentual de desistentes (13\%), mas também, nos que não tiveram interesse pelo projeto $(58,6 \%)$.

Embora, a priori, houvesse o critério de que para serem aprovados os estudantes que fizeram o seletivo deveriam obter nota superior a 7, decidiu-se pela inclusão daqueles que tiveram resultado inferior, devido ao déficit de conhecimento apresentado pela grande maioria quanto aos assuntos propostos e a necessidade de tal aprendizado para a carreira profissional e científica.

Gráfico 2. Resultados do teste avaliativo.

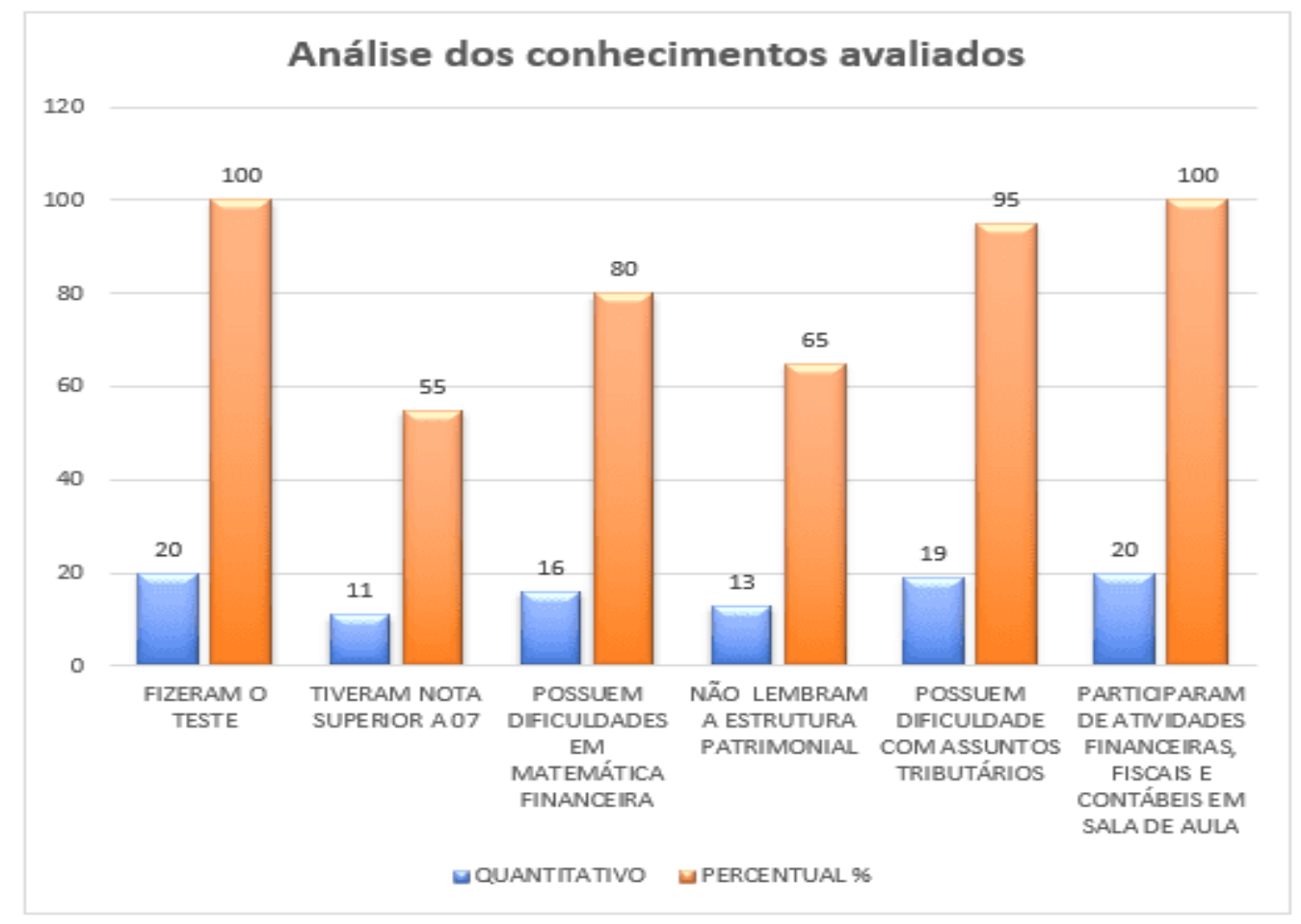

Fonte: elaborado pelo autor.

Disponível em: https://www.nucleodoconhecimento.com.br/contabilidade/contabilizando- 
Embora estes indicadores demonstrem falta de conhecimento dos assuntos propostos por parte de quase metade dos que fizeram o seletivo $(n=9)$, todos os estudantes envolvidos no processo já participaram de atividades e disciplinas que trabalham a educação financeira, fiscal e contábil (Figura 3).

Figura 3. Estudantes aprendendo a elaborar declaração de imposto de renda ( $1^{\text {a }}$ etapa).

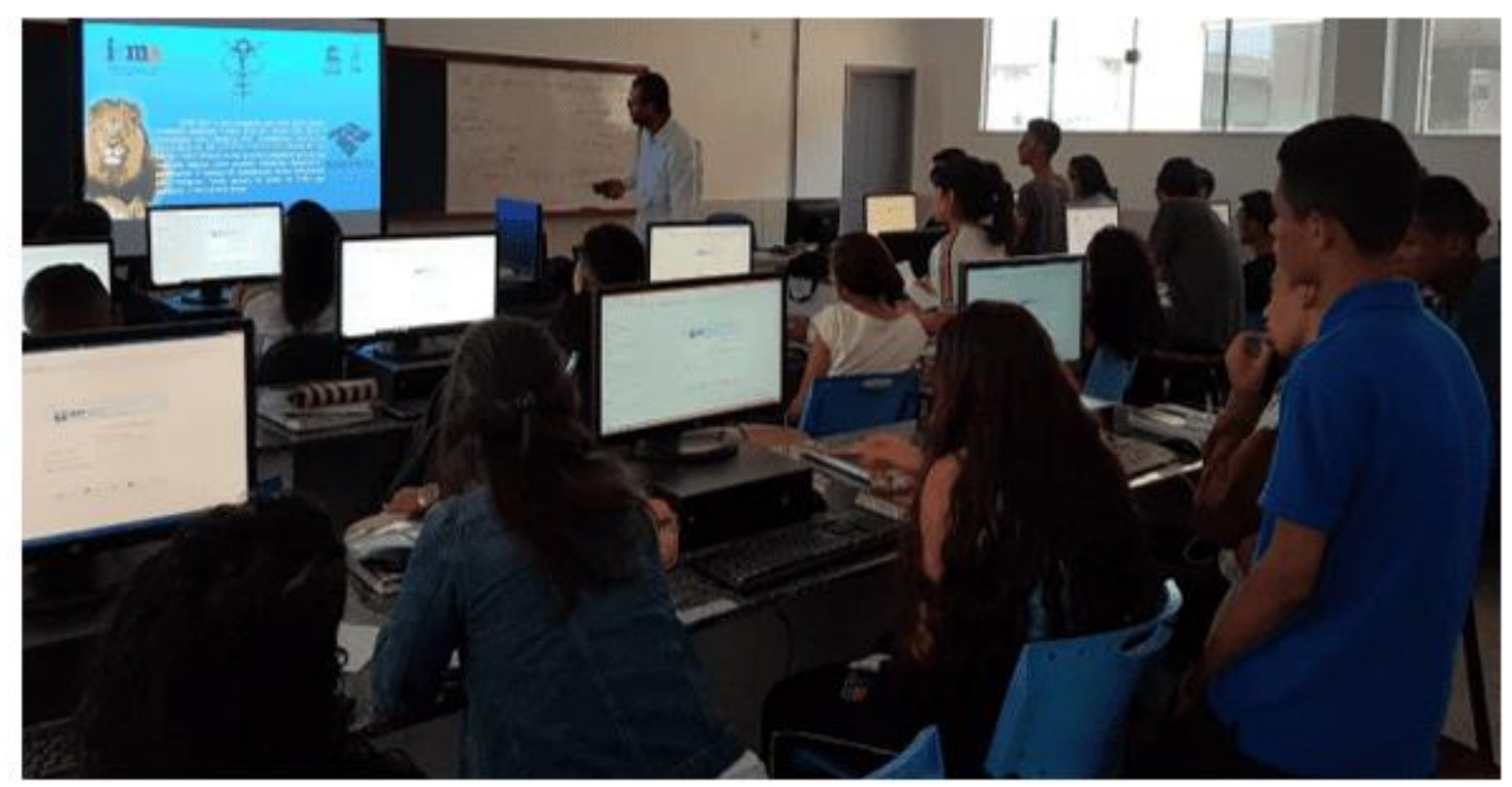

Fonte: Autor, 2019

Tais informações levantam a hipótese de que devido à complexidade e extensão do tema abordado, além baixa carga horária trabalhada em sala de aula, pode haver a necessidade da oferta de outras disciplinas, pesquisas (figura 4) e capacitações que complementem esse conhecimento. Há ainda a hipótese de que muitos estudantes acabam se dedicando apenas nos períodos de prova, no intuito de apresentar boas notas, não se importando com a absorção dos conteúdos propostos e consequentemente, não adquirindo os conhecimentos necessários para a resolução do teste avaliativo. 
Figura 4. 3a Feira de Profissões e SEMIC IEMA 2019: apresentação de trabalho sobre os incentivos fiscais atrelados ao agronegócio no Maranhão (Atividade complementar. $2^{\mathrm{a}}$ etapa).

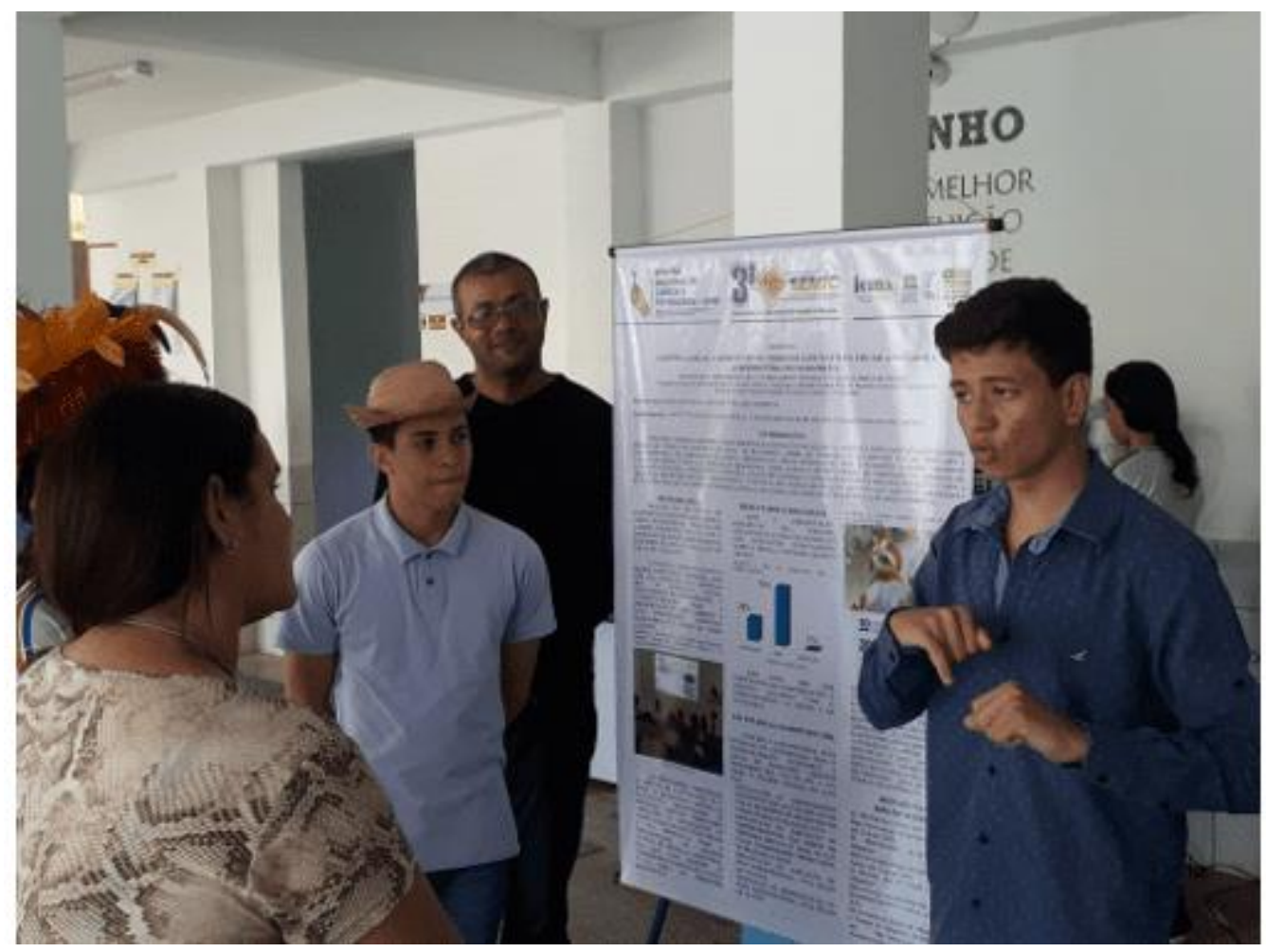

Fonte: Autor, 2019.

Outra hipótese em questão é a falta de atividades que contemplem tais conhecimentos no ensino fundamental e que pode ter influenciado os resultados, além do fato de que todos os estudantes ao ingressar na rede IEMA, precisam escolher um dos cursos técnicos disponíveis pela Unidade Plena, o que nem sempre é a 1a opção e pode não apenas gerar desinteresse pelo curso escolhido, mas também, desestimular e comprometer a aprendizagem técnica aplicada no cotidiano desses estudantes.

Entretanto, mesmo com a pesquisa ainda não estando concluída, entende-se que alguns objetivos começam a ser alcançados, tendo em vista que os estudantes já acessam softwares financeiro, cadastram fornecedores, clientes, produtos e serviços, registram compras e vendas, analisam notas fiscais e calculam juros simples e compostos (Figura 5).

RC: 63588

Disponível em: https://www.nucleodoconhecimento.com.br/contabilidade/contabilizandoconhecimento 
Figura 5. Capacitação no módulo financeiro (2 $2^{\mathrm{a}}$ etapa).

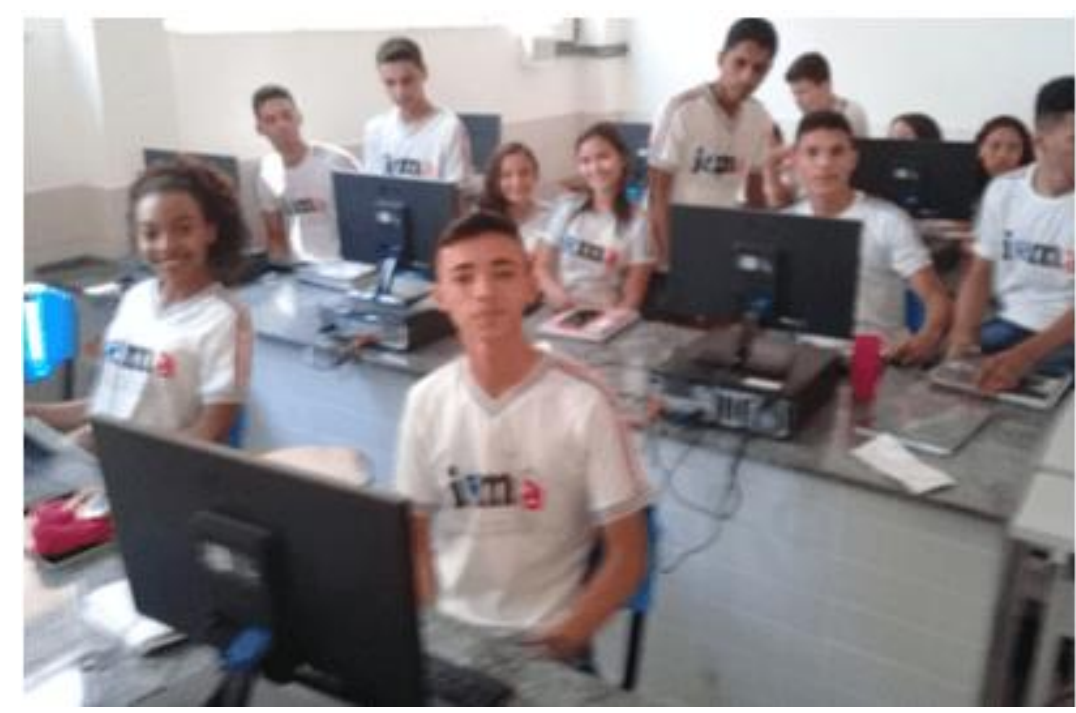

Fonte: Autor, 2019.

Compreende-se que seria muito mais vantajoso para as empresas que desejam contratar trabalhadores, absorverem profissionais que já possuam o conhecimento adequado, do que disponibilizar treinamento técnico àqueles que ainda não o possuem, otimizando o custo benefício (FONSECA et al., 2014). Além disso, os estudantes também participam e apresentam trabalhos em eventos científicos (Figura $6)$. 
Figura 6. Apresentação do projeto na II Semana Acadêmica UEMA 2019 (Atividade complementar. $2^{\mathrm{a}}$ etapa).

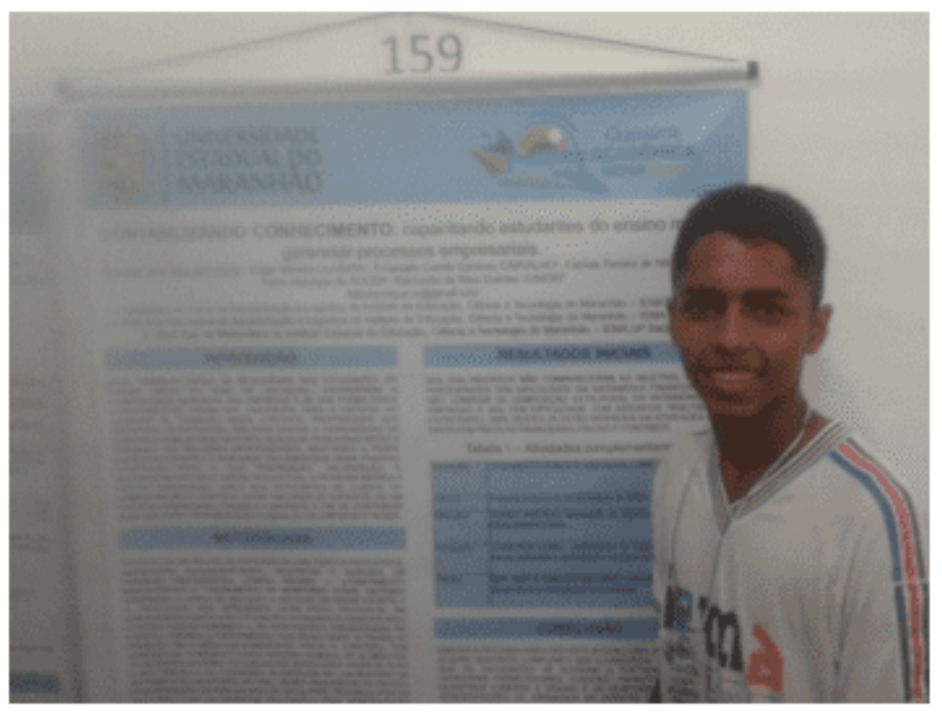

Fonte: Autor, 2019.

Todo trabalho que busca conhecer a realidade das empresas se justifica pela grande carência de informações nesta área e pela sua importância para a economia de uma região (EINSFELD, 2011). Além disso, os estudantes que foram para o estágio prévio já conseguem aplicar alguns dos conhecimentos adquiridos na prática, o que de certa forma também justifica a realização da pesquisa. É importante também destacar a necessidade da utilização de produtos digitais nas instituições de ensino, o que pode facilitar o acesso ao conhecimento tecnológico, promoção de parcerias, ampliação de networking e geração de emprego e renda (OTERO, 2010). Vale ainda ressaltar que o projeto contabilizando conhecimento foi no $1^{\circ}$ semestre de 2019, premiado em $3^{\circ}$ lugar no prêmio Sebrae de Educação Empreendedora (Figura 7) pelas práticas desenvolvidas na sua $1^{1} \stackrel{a}{ }$ etapa de realização. 
Figura 7. Cerimônia de premiação: Prêmio Sebrae Educação Empreendedora 2019.

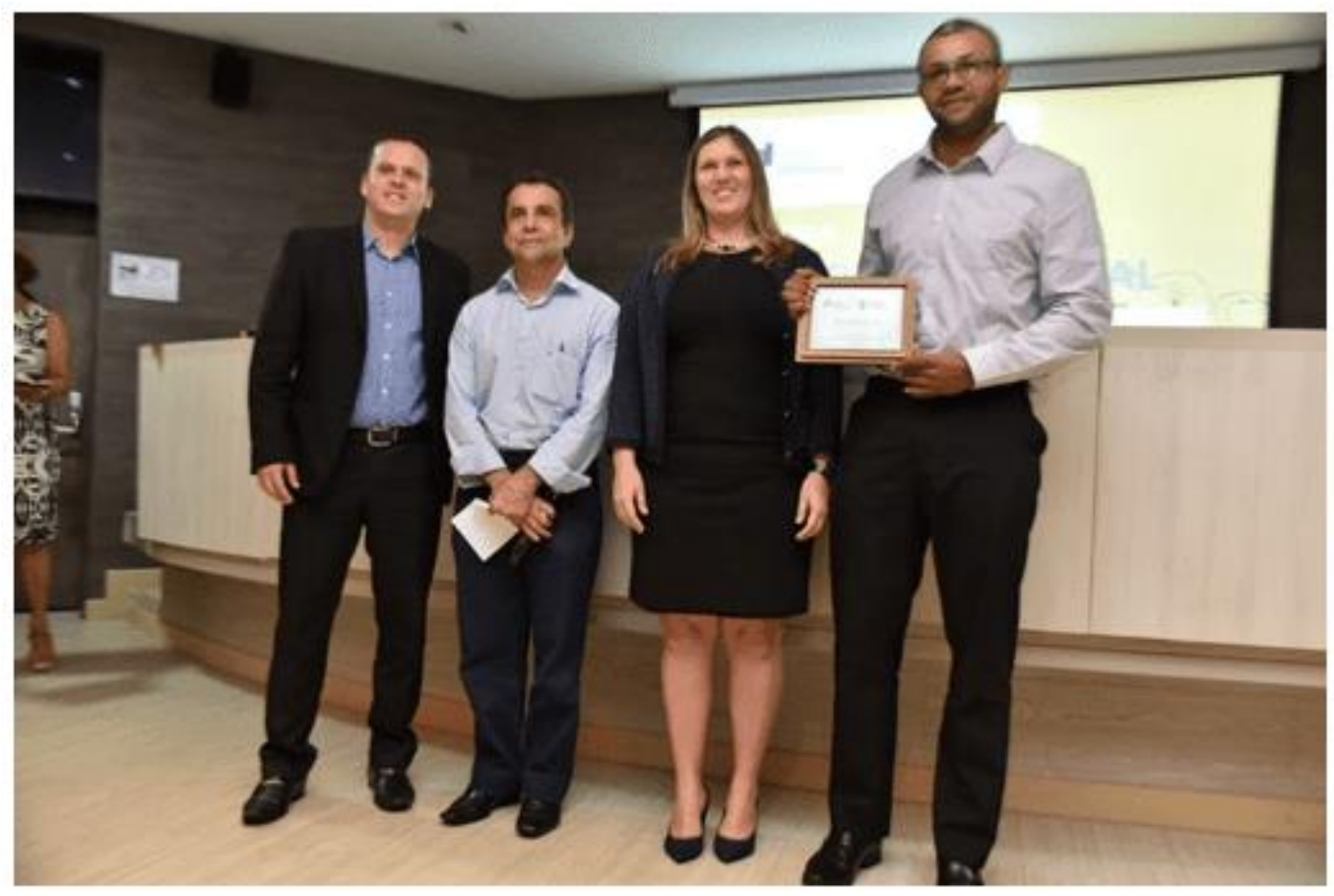

Fonte: Autor, 2019.

\section{CONCLUSÃO}

Embora os estudantes já tenham cursado disciplinas que envolvem o tema em questão e obtido aprovação, bem como, participado de eventos que contemplem a difusão da educação financeira, fiscal e contábil, entende-se que há necessidade de outras disciplinas, pesquisas e capacitações na área para melhor aproveitamento do conteúdo. Também observa-se que há um déficit educacional quanto às atividades complexas e de raciocínio lógico que vem desde o ensino fundamental, o que de certa forma, pode estar refletindo negativamente nas aprendizagens técnicas do ensino médio. Entretanto, mesmo com o desenvolvimento ainda que parcial da pesquisa, muitos resultados positivos já começam a aparecer, uma vez que os estudantes envolvidos já apresentam um grau de conhecimento significativo sobre gerenciamento financeiro, desenvolvem outras pesquisas derivadas deste projeto e ainda apresentam trabalhos em eventos acadêmicos e científicos. Dessa forma, entende-se que a execução do projeto é de grande relevância na preparação dos estudantes para o 
mercado de trabalho e para o desenvolvimento de pesquisas sobre o tema, uma vez que garante conhecimentos técnicos necessários para as demandas gerenciais das empresas e ainda os apresenta em eventos científicos. No entanto, é necessário aguardar o término do projeto, que foi impactado diretamente pela paralização das atividades escolares no Estado do Maranhão devido à pandemia do coronavirus, a fim de obter-se resultados mais completos. Além disso, percebe-se que é importante a continuação de projetos desse caráter e que capacitem os estudantes de nível técnico.

\section{REFERÊNCIAS}

EINSFELD, Eduardo B. Contabilidade Gerencial: instrumento de negócio para a gestão de micro e pequenas empresas. Porto Alegre, 2011. Disponível em: https://lume.ufrgs.br/bitstream/handle/10183/34898/000784761.pdf?sequence=1\&isA llowed=y. Acesso em 11 Jun.2019.

FONSECA et al. A importância do Contador nas organizações. XI Simpósio de Excelência em Gestão e Tecnologia. SEGET. Rio de Janeiro, 2014. Disponível em: https://www.aedb.br/seget/arquivos/artigos14/32720337.pdf. Acesso em: 11 Jun. 2019.

OTERO, Walter, R. I. Transferência de conhecimento tecnológico da universidade para o setor produtivo em Portugal. X Coloquio Internacional sobre Géstion Universitária en America del Sur. "Balance y prospectiva de la Educación Superior em el marco de los Bicentenarios de America del Sur". Mar del Plata, 2010. Disponível em: https://core.ac.uk/download/pdf/30378088.pdf. Acesso em 11 Jun. 2019.

Questionário Socioeconômico ENCCEJA 2013. Disponível em: http://download.inep.gov.br/educacao_basica/encceja/questionario_socioeconomico/ 2013/questionario_socioeconomico_encceja_2013.pdf. Acesso em: 03 de Jun. 2019. 


\section{APÊNDICE I}

Questionário socioeconômico e de identificação das dificuldades de acesso ao mercado de trabalho.

1-Quantas pessoas moram com você? (Incluindo filhos, irmãos, parentes e amigos (Marque apenas uma resposta)
(A) Moro sozinho
(B) Uma a três
(C) Quatro a sete
(D) Oito a dez
(E) Mais de dez

2- A casa onde você mora é? (Marque apenas uma resposta)
(A) Própria
(B) Alugada
(C) Cedida

3- Sua casa está localizada em? (Marque apenas uma resposta)
(A) Zona rural.
(B) Zona urbana
(C) Comunidade indígena.
(D) Comunidade quilombola. 
4- Qual é o nível de escolaridade do seu pai? (Marque apenas uma resposta)
(A) Da 1aa 4⿳亠丷a série do Ensino Fundamental (antigo primário)
(B) Da 5aa 8aㅗ série do Ensino Fundamental (antigo ginásio)
(C) Ensino Médio (antigo 2º grau)
(D) Ensino Superior
(E) Especialização
(F) Não estudou
(G) Não sei

5- Qual é o nível de escolaridade da sua mãe? (Marque apenas uma resposta)
(A) Da 1à 4ª $^{\mathrm{a}}$ série do Ensino Fundamental (antigo primário)
(B) Da 5ª̀ à 8ª série do Ensino Fundamental (antigo ginásio)
(C) Ensino Médio (antigo 2ํgrau)
(D) Ensino Superior
(E) Especialização
(F) Não estudou
(G) Não sei

6- Somando a sua renda com a renda das pessoas que moram com você, quanto é, aproximadamente, a renda familiar mensal? (Marque apenas uma resposta)

(A) Nenhuma renda. 
(B) Até 1 salário mínimo (até $\mathrm{R} \$ 678,00$ ).

(C) De 1 a 3 salários mínimos (de $R \$ 678,01$ até $R \$ 2.034,00$ ).

(D) De 3 a 6 salários mínimos (de $R \$ 2.034,01$ até $R \$ 4.068,00$ ).

(E) De 6 a 9 salários mínimos (de $R \$ 4.068,01$ até $R \$ 6.102,00$ ).

(F) De 9 a 12 salários mínimos (de $R \$ 6.102,01$ até $R \$ 8.136,00$ ).

(G) De 12 a 15 salários mínimos (de $R \$ 8.136,01$ até $R \$ 10.170,00$ ).

(H) Mais de 15 salários mínimos (mais de $R \$ 10.170,01$ ).

7- Qual a sua renda mensal, aproximadamente? (Marque apenas uma resposta)

(A) Nenhuma renda.

(B) Até 1 salário mínimo (até $\mathrm{R} \$ 678,00$ ).

(C) De 1 a 3 salários mínimos (de $R \$ 678,01$ até $R \$ 2.034,00$ ).

(D) De 3 a 6 salários mínimos (de $R \$ 2.034,01$ até $R \$ 4.068,00$ ).

(E) De 6 a 9 salários mínimos (de $R \$ 4.068,01$ até $R \$ 6.102,00$ ).

(F) De 9 a 12 salários mínimos (de $R \$ 6.102,01$ até $R \$ 8.136,00$ ).

(G) De 12 a 15 salários mínimos (de $R \$ 8.136,01$ até $R \$ 10.170,00$ ).

(H) Mais de 15 salários mínimos (mais de $R \$ 10.170,01$ ).

De acordo com a sua opinião, responda:

8- 0 que uma pessoa precisa fazer para conseguir seu primeiro emprego?

\section{9- 0 que uma pessoa precisa fazer para crescer profissionalmente?}


10- Quais as principais dificuldades encontradas para realização das atividades do estágio profissionalizante?

\section{APÊNDICE II - TESTE AVALIATIVO}

NOME:

CURSO:

\section{Questões}

1. Na sua opinião, qual a principal diferença entre juros simples e compostos?

2. Um investidor aplicou a quantia de $\mathrm{R} \$ 500,00 \mathrm{em}$ um fundo de investimento que opera no regime de juros simples. Após 6 meses o investidor verificou que o montante era de $R \$ 560,00$. Qual a taxa de juros desse fundo de investimento?

3. Uma pessoa aplicou o capital de $R \$ 1.200,00$ a uma taxa de $2 \%$ ao mês durante 14 meses no regime de juros compostos. Determine o montante dessa aplicação.

4. Quais as principais características de um tributo?

5. Ao fabricar e comercializar determinados produtos, uma empresa acaba criando situações (fatos geradores) para a incidência alguns tributos, quais são?

6. Contribuições Especiais e Parafiscais: são tributos brasileiros incluídos na espécie tributária chamada contribuição especial no interesse de categorias econômicas ou profissionais.

De acordo com o enunciado, quais entidades são financiadas por esse tipo de tributação?

7. De acordo com seus conhecimentos contábeis, o que significa PATRIMÔNIO?

8. Desenhe abaixo um Balanço Patrimonial com todos os seus componentes: 
9. De que forma o programa EXCEL desenvolvido pela empresa Microsoft pode contribuir com a gestão empresarial?

10. Quais os benefícios para as empresas que utilizam a internet de forma segura para a transferência de informações gerenciais?

Enviado: Julho, 2020.

Aprovado: Outubro, 2020. 